\title{
Spatial patterns of climatic changes in the Eurasian north reflected in Siberian larch tree-ring parameters and stable isotopes
}

\author{
OLGA V.SIDOROVA*†, ROLF T. W. SIEGWOLF*, MATTHIAS SAURER*,

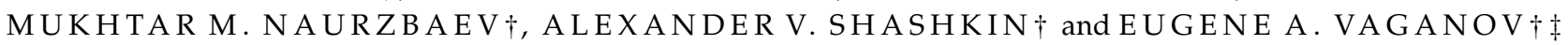 \\ *Paul Scherrer Institute, Villigen 5232, Switzerland, $\dagger$ V.N. Sukachev Institute of Forest SB RAS, Akademgorodok, Krasnoyarsk \\ 660036, Russia, †Siberian Federal University, Svobodniy pr, 79, Krasnoyarsk 660049, Russia
}

\begin{abstract}
A spatial description of climatic changes along circumpolar regions is presented based on larch tree-ring width (TRW) index, latewood density (MXD), $\delta^{13} \mathrm{C}, \delta^{18} \mathrm{O}$ of whole wood and cellulose chronologies from eastern Taimyr (TAY) and north-eastern Yakutia (YAK), Russia, for the period 1900-2006, in comparison with a $\delta^{13} \mathrm{C}$ cellulose chronology from Finland (FIN) and a $\delta^{18} \mathrm{O}$ ice core record from Greenland (GISP2). Correlation analysis showed a strong positive relationships between TRW, MXD, stable isotope chronologies and June, July air temperatures for TAY and YAK, while the precipitation signal was reflected differently in tree-ring parameters and stable isotope data for the studied sites. Negative correlations were found between July, August precipitation from TAY and stable isotopes and MXD, while May, July precipitations are reflected in MXD and stable isotopes for the YAK. No significant relationships were found between TRW and precipitation for TAY and YAK. The areas of significant correlations between July gridded temperatures and TRW, MXD and stable isotopes show widespread dimension from east to west for YAK and from north to south for TAY. The climate signal is stronger expressed in whole wood than in cellulose for both Siberian regions. The comparison analysis between $\delta^{13} \mathrm{C}$ cellulose chronologies from FIN and TAY revealed a similar declining trend over recent decades, which could be explained by the physiological effect of the increasing atmospheric $\mathrm{CO}_{2}$. TRW, MXD and $\delta^{13} \mathrm{C}$ chronologies from TAY and YAK show a negative correlation with North Atlantic Oscillation index, while the $\delta^{18} \mathrm{O}$ chronologies show positive correlations, confirming recent warming trend at high latitudes. The strong correlation between GISP2 and $\delta^{18} \mathrm{O}$ of cellulose from YAK chronologies reflects the large-scale climatic signal connected by atmospheric circulation patterns expressed by precipitation.
\end{abstract}

Keywords: climate change, $\delta^{13} \mathrm{C}$ and $\delta^{18} \mathrm{O}$ of wood and cellulose, Greenland ice core, late wood density, North Atlantic Oscillation, northern Finland, permafrost, Siberian north (Russia), spatial patterns, tree-ring width

Received 9 March 2009 and accepted 29 May 2009

\section{Introduction}

The instrumental data show a temperature increase during the last 100 years for many regions along circumpolar northern latitudes (ACIA, 2005; IPCC, 2007). The magnitude of temperature obtained from

Correspondence: Olga V. Sidorova, Paul Scherrer Institute, Villigen 5232, Switzerland, tel. + 73912495 053; + 4156310 2903, fax + 7 3912433 686; + 4156310 4525, e-mails:

ovsidorova@forest.akadem.ru; olga.sidorova@psi.ch instrumental data is higher than shown in reconstructed models obtained from different indirect sources of paleoclimate information such as ice core, lake sediments and tree rings (IPCC, 2007; D'Arrigo et al., 2008). It is therefore important to establish new proxy series to increase the reliability of the reconstructed climate signal. Of these proxies, tree-ring chronologies (width, density and stable isotopes) allow to reconstruct temperature with temporal resolution up to 1 year for several millennia (Hughes et al., 1999; Vaganov \& Shiyatov, 1999; Naurzbaev et al., 2002; McCarroll \& Loader, 2004; Sidorova et al., 2008). 
As well known, trees growing at the northern tree line in the permafrost zones are very sensitive to climate changes due to limiting temperature regimes (Vaganov et al., 1999; Briffa et al., 2001). The tree-ring width and tree-ring density therefore provide summer temperature information, but relatively little is known about precipitation changes. However, under low amounts of precipitations and relatively warm and dry conditions trees respond to limited water resources by reducing stomatal conductance, resulting in a diminished intercellular $\mathrm{CO}_{2}$ concentration. This leads to a reduced ${ }^{13} \mathrm{C}$ discrimination (Farquhar et al., 1989) and increased $\delta^{18} \mathrm{O}$ values (Farquhar \& Lloyd, 1993). Oxygen isotopes in tree rings are mainly influenced by the isotope signal in precipitation (Craig, 1961), which represents the source water for trees. Enrichment in $\delta^{18} \mathrm{O}$ occurs in the needles/leaf during transpiration, which may be enhanced under drought conditions (Yakir \& Sternberg, 2000). A mixed signal of source and needle water enrichment is finally stored in the wood and cellulose of the tree rings (Saurer et al., 1997; Roden \& Ehleringer, 2000). The stable isotope chronologies $\left(\delta^{13} \mathrm{C}, \delta^{18} \mathrm{O}\right)$ obtained from the Siberian north thus show significant relationships not only with temperature (like tree-ring parameters) but also with precipitation (unlike tree-ring parameters) (Sidorova et al., 2008). Most of the Siberian sites are covered by permafrost, which plays a key role in the stabilization of the climatic system (ACIA, 2005). The $\delta^{18} \mathrm{O}$ signal could be weak in the year-to-year variability due to the complex soil hydrology causing an increased water availability from permafrost thawing and mixing of winter precipitation and summer rainfall (Boike et al., 1998; Sugimoto et al., 2002). However, it is possible to expect strong long-term signals connected with annual precipitation and atmospheric circulation patterns (Hurrell, 1995; Welker et al., 2005). The application of the stable isotope analysis in combination with classical dendrochronology is steadily increasing because stable isotopes provide complementary information about climatic variabilities (McCarroll \& Pawellek, 2001; Saurer et al., 2002; McCarroll \& Loader, 2004; Gagen et al., 2006; Skomarkova et al., 2006; Kirdyanov et al., 2008; Sidorova et al., 2008).

In this paper, we report about the response of larch trees to climatic changes on the eastern Taimyr (Russia) (TAY) during the last century using tree-ring width, latewood density and stable isotope wood and cellulose $\left(\delta^{13} \mathrm{C}, \delta^{18} \mathrm{O}\right)$ chronologies. For investigating large-scale climate patterns and common signals between subarctic regions we used tree-ring and stable isotope chronologies from north-eastern Yakutia (Sakcha Republic) (YAK) (Hughes et al., 1999; Sidorova \& Naurzbaev, 2002; Sidorova et al., 2008), $\delta^{13} \mathrm{C}$ cellulose series from Finland (FIN) (Gagen et al., 2007, 2008) and Greenland ice core data (GISP 2) (Meese et al., 1994). Moreover, we analyzed the influence of North Atlantic Oscillation (NAO) patterns on tree-ring parameters and stable isotope chronologies from the studied Siberian sites. The use of different proxy data will improve our understanding of factors influencing on growth of conifer trees in the northern regions and allow to build high quality climate reconstructions into the past.

\section{Materials and methods}

\section{Study site and sample collection}

Discs samples from living larch trees (Larix gmelinii Rupr.) were collected on the eastern part of Taimyr Peninsula, Hatanga region, Kotuy valley $\left(70^{\circ} 38^{\prime} \mathrm{N}-\right.$ $\left.103^{\circ} 21^{\prime} \mathrm{E}\right)$ (TAY) (Fig. 1). The samples were taken at a height of $1.3 \mathrm{~m}$ in the north-eastern slope of the plateau, $300 \mathrm{~m}$ a.s.l. The distance between the trees was $5-8 \mathrm{~m}$. The soil was covered with a moss layer of $4-5 \mathrm{~cm}$.

The land surface of the study site is characterized by coarse rocks on continues permafrost layer. The maximal depth of permafrost thawing is $40 \mathrm{~cm}$ in the middle of August. The climate is extra continental with short vegetation seasons (up to 90 days), which could be variable due to date of snow melt and initiation of cambial activity (Abaimov et al., 1997; Vaganov et al., 1999). The tree growth on the studied site is limited by June and July air temperature (Vaganov et al., 1996; Abaimov et al., 1997; Naurzbaev et al., 2002). The warmest month in the studied region is July with an average air temperature up to $12.6^{\circ} \mathrm{C}$. The average amount of annual precipitation is $278 \mathrm{~mm}$ for the period of 1934-2006. Most part of the precipitation falls in JulyAugust. The mean annual temperature is $-12.8^{\circ} \mathrm{C}$.

\section{Climatic data}

Monthly temperature and precipitation data for TAY are available for the period 1929-2006 from the 'Hatanga' weather station: $\left(71^{\circ} 98^{\prime} \mathrm{N}, 102^{\circ} 47^{\prime} \mathrm{E}, 33 \mathrm{~m}\right)$, http:// climexp.knmi.nl. For the analysis of data from YAK, we used weather station data from 'Chokurdach', located approximately $200 \mathrm{~km}$ from the study site $\left(70^{\circ} 62^{\prime} \mathrm{N}, 147^{\circ} 88^{\prime} \mathrm{E}, 61 \mathrm{~m}\right)$. The data were available for the period 1901-2003. The comparative analysis of climatological data between two Siberian sites was carried out for the common period from 1929-2003.

Five-day averages of air temperature from weather stations 'Chokurdach' and 'Hatanga' were used for detailed analyses for comparisons with isotope chronologies. The data were available for the period 1945-1989.

For the analysis of spatial patterns we used gridded July air temperature (GJT) data $2.1^{\circ} \times 0.5^{\circ}, P<10 \%$ for the period 1901-2001. 


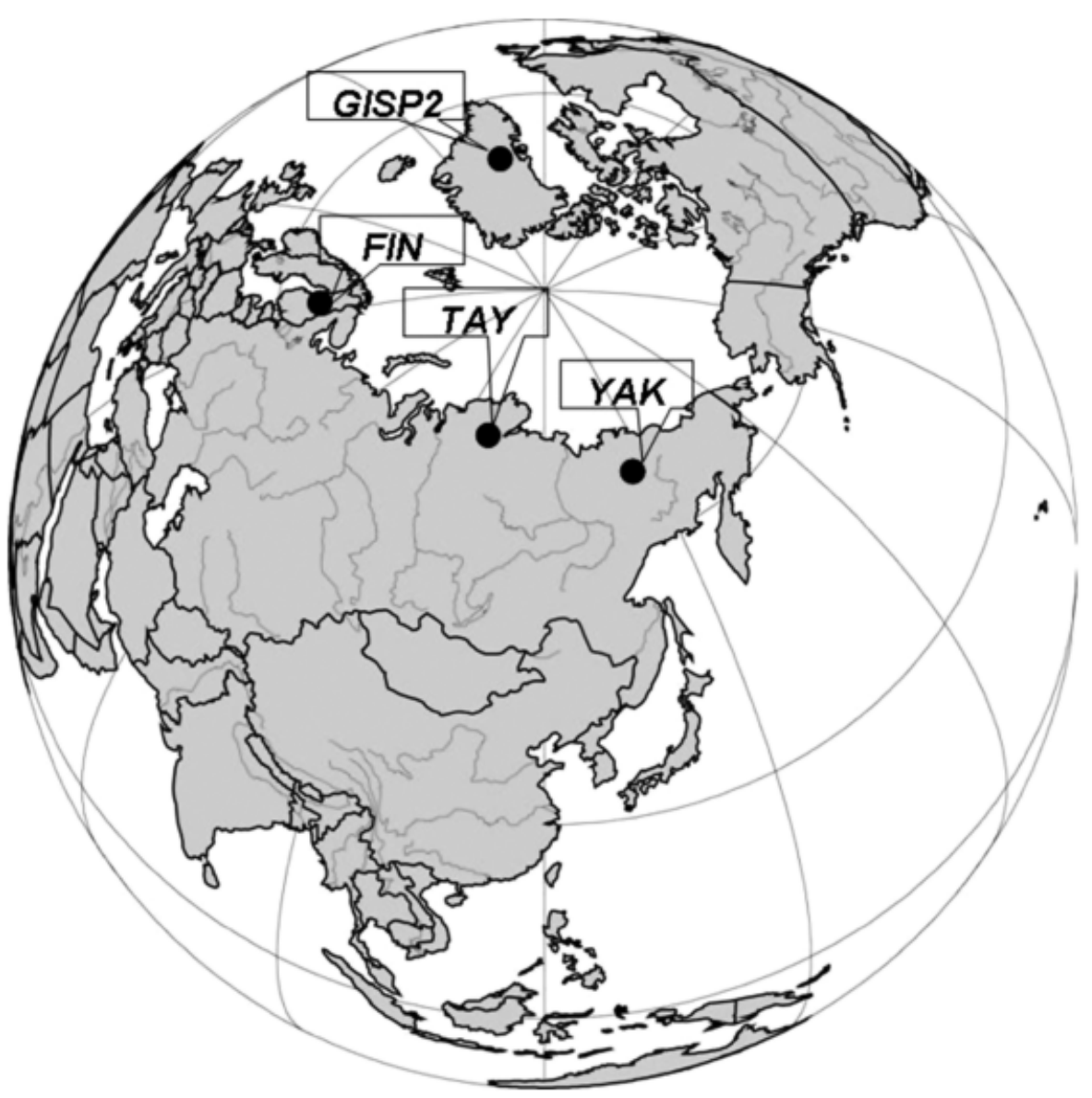

Fig. 1 Location of the study site in eastern Taimyr, Russia (TAY) and sites, which were used for comparative analyses of stable isotope, tree-ring width and late wood density chronologies from the Sakcha Republic, north-eastern Yakutia, Russia (YAK) (Hughes et al., 1999; Kirdyanov et al., 2008; Sidorova et al., 2008); $\delta^{13} \mathrm{C}$ of cellulose chronology is from Laanila, northern Finland (FIN) (Gagen et al., 2007, 2008) and $\delta^{18} \mathrm{O}$ chronology from Greenland ice core (GISP2).

Data from NAO indices were obtained from the Climatic Research Unit site, http://www.cru.uea. ac.uk/cru/data/nao.htm, for the period 1821-2000. The NAO is one of the Northern Hemisphere's major multiannual climate fluctuations and traditionally defined as the normalized pressure difference between a station on the Azores and one on Iceland. An extended version of the index can be derived for the winter half using a station in the southwestern part of the Iberian Peninsula (Hurrell, 1995).

Hamming smoothing (Blackman \& Tukey, 1958) with 11-year window was used for revealing long-term climatic signals between all chronologies.

\section{Compared sites}

To reveal common climatic signals along the subarctic we used available stable isotope $\left(\delta^{13} \mathrm{C}, \delta^{18} \mathrm{O}\right)$, tree-ring width and latewood density chronologies obtained for the north-eastern Yakutia, Sakcha Republic $\left(70^{\circ} \mathrm{N}-148^{\circ} \mathrm{E}\right)$
(YAK) (Hughes et al., 1999; Sidorova \& Naurzbaev, 2002; Kirdyanov et al., 2008; Sidorova et al., 2008), a $\delta^{13} \mathrm{C}$ cellulose chronology from northern Finland (FIN) (Gagen et al., 2007, 2008; M. H. Gagen, personal communication) and a $\delta^{18} \mathrm{O}$ ice core chronology from Greenland (GISP2) (Meese et al., 1994) (Fig. 1). The ice core data (GISP2 Greenland Ice Sheet Project 2; $72^{\circ} 60^{\prime} \mathrm{N}-38^{\circ} 50^{\prime} \mathrm{W}$, 3200 ma.s.l.) were obtained from the web site http:// www.ncdc.noaa.gov/paleo/icecore/greenland/summit/document/gispisot.htm

\section{Dendrochronological analysis}

Tree-ring widths were measured using semiautomatic devices with accuracy $0.01 \mathrm{~mm}$ for 20 living trees for the period 1846-2006. Cross-dating of samples and statistical calculations were carried out in standard dendrochronological software (TSAP, DPL, ARSTAN) (Cook \& Kairiukstis, 1990). These trees were added to the treering width chronology constructed by Naurzbaev et al. 
(2002). This combined chronology was used for the further analysis.

The measurement of maximum latewood density was carried out using densitometer DENDRO 2003 at the Swiss Federal Institute of Snow Landscape and Avalanches, WSL (Sidorova, 2004). The maximum latewood density chronology was built using eight cores of living trees for the period 1717-2000. Based on high coherence and statistical relationships the late wood density chronology from eastern Taimyr (Kotuy), the chronology was combined with latewood chronologies obtained by Schweingruber (1996) for the same region.

\section{The stable isotope analysis}

For the stable isotope analysis of TAY site we selected four trees, which were analyzed separately for the ${ }^{13} \mathrm{C} /{ }^{12} \mathrm{C}$ and ${ }^{18} \mathrm{O} /{ }^{16} \mathrm{O}$ isotopic ratios in whole wood and cellulose for the period 1900-2006. The mean age of trees used for the stable isotope analysis was 160 years. The first 50 rings closest to the pith were excluded from analyses due to the juvenile effect (McCarroll \& Loader, 2004; Gagen et al., 2008; Sidorova et al., 2008). The resin from the wood samples was extracted in ethanol using a Soxhlet apparatus over $36 \mathrm{~h}$ and after that the samples were washed and dried. The whole wood samples were split with annual resolution and milled to a fine powder. Samples of cellulose after extraction (Loader et al., 1997) were weighed into tin capsules for analysis.

We determined the $\delta^{13} \mathrm{C}$ and $\delta^{18} \mathrm{O}$ values for whole wood and cellulose using a delta-S mass spectrometer (Finnigan MAT, Bremen, Germany) linked with two elemental analyzers (EA-1108 and EA-1110; Carlo Erba, Rodano, MI, Italy), one set to combustion and one to pyrolysis mode, via a variable open split interface (CONFLO-II, Finnigan MAT) at the stable isotope facility at the Paul Scherrer Institute, Villigen, Switzerland. The isotopic values were expressed in the delta notation relative to the international standards: $\delta_{\text {sample }}=\left(R_{\text {sample }} / R_{\text {standard }}-1\right) \times 1000$, where $R_{\text {sample }}$ is the molar fraction of ${ }^{13} \mathrm{C} /{ }^{12} \mathrm{C}$, or ${ }^{18} \mathrm{O} /{ }^{16} \mathrm{O}$ ratio of the sample and $R_{\text {standard, }}$ of the standards VPDB for carbon and VSMOW for oxygen.

The $\delta^{13} \mathrm{C}$ of whole wood and cellulose were corrected for the decline of the ${ }^{13} \mathrm{C} /{ }^{12} \mathrm{C}$ ratio of atmospheric $\mathrm{CO}_{2}$ due to release of fossil fuel and land use change. The $\delta^{13} \mathrm{C}$ of atmospheric $\mathrm{CO}_{2}$ was obtained from ice cores and direct atmospheric measurements at the Mauna Loa Observatory, Hawaii (Francey et al., 1999; http:// www.esrl.noaa.gov/gmd/ccgg/globalview/co2c13/ co2c13_intro.html).

We subtracted the difference between preindustrial and present-day $\delta^{13} \mathrm{C}$ of atmospheric $\mathrm{CO}_{2}$ from the raw isotope series for each year.

\section{Results}

Tree-ring width, maximum density and stable isotope chronologies from eastern Taimyr

The larch tree-ring width (TRW) chronology constructed for TAY by Naurzbaev et al. (2002) was prolonged up to 2006 using 20 tree samples. Herein we present tree-ring width and maximum latewood density (MXD) chronologies (Fig. 2a) covering the same period (1900-2006), which we used for the analysis of carbon and oxygen isotope ratios for whole wood and cellulose (Fig. 2b). TRW and MXD show similar trends in year-to-year and long-term variability with correlations between each other up to 0.62 for 1900-2001 (Table 1, Fig. 2a).

We determined $\delta^{13} \mathrm{C}$ and $\delta^{18} \mathrm{O}$ of whole wood and cellulose for four individual trees separately. The average of isotope chronologies was constructed (Fig. 2b) based on strong relationships between the four different trees for carbon $(r=0.59-0.64 ; P<0.05$ for whole wood and cellulose) and for oxygen $(r=0.49-0.63 ; P<0.05$ for whole wood and cellulose), respectively. The mean difference between whole wood and cellulose for carbon is $1.64 \%$ and for oxygen $3.46 \%$. The mean stable isotope values for carbon are $-25.40 \%$ and $-23.76 \%$ for whole wood and cellulose and $17.88 \%$ and $21.34 \%$ for oxygen, respectively. The $\delta^{13} \mathrm{C}$ chronologies for both wood and cellulose have an increasing trend until 1960 but after that they strongly decline. This clear decrease in carbon isotope data was observed although all data have been corrected for the decline in $\delta^{13} \mathrm{C}$ of the atmospheric $\mathrm{CO}_{2}$. The whole wood $\delta^{18} \mathrm{O}$ chronology shows a slight decrease over the 20th century while cellulose is relatively constant and shows a slightly increasing trend after 1960.

The MXD chronology shows significant correlations with all isotope chronologies except for the $\delta^{18} \mathrm{O}$ in cellulose (see Table 1a), while the TRW chronology shows significant correlations only with the isotope ratios of whole wood. The correlation coefficients indicate a high synchronicity between whole wood and cellulose for carbon as well as for oxygen isotopes (Table 1a).

\section{Tree-ring width, maximum density and stable isotope chronologies from north-eastern Yakutia}

We calculated correlation coefficients between TRW from earlier studies (Hughes et al., 1999; Sidorova \& Naurzbaev, 2002), MXD (Kirdyanov et al., 2007; Sidorova et al., 2008) and $\delta^{13} \mathrm{C}$ and $\delta^{18} \mathrm{O}$ in whole wood and cellulose (Sidorova et al., 2008) from YAK for the period 1900-2001 (Table 1b). The correlation analysis showed similar relationships between TRW, MXD and 

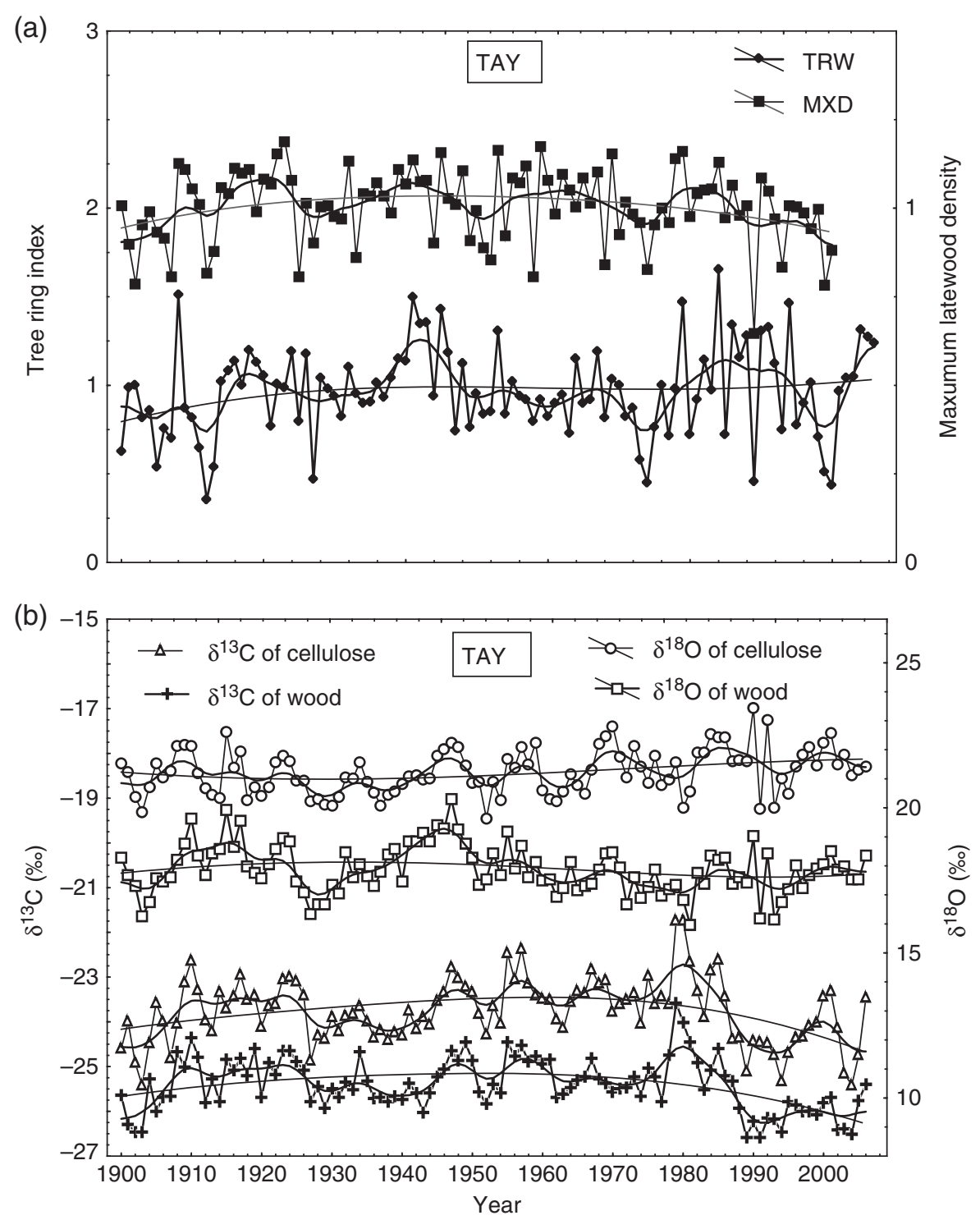

Fig. 2 (a) Standardized tree-ring width (TRW) and maximum latewood density (MXD) chronologies for the periods of 1900-2006 and 1900-2001, correspondingly; (b) $\delta^{13} \mathrm{C}$ and $\delta^{18} \mathrm{O}$ of whole wood and cellulose chronologies in comparison for the period $1900-2006$.

stable isotope chronologies as they were found for TAY (Table 1a), but we did not find significant correlations between TRW and stable isotope chronologies (Table 1b). Significant correlations were observed only between smoothed TRW and $\delta^{13} \mathrm{C}$ whole wood and cellulose chronologies $(r=0.29$ and $0.35 ; P<0.05)$, respectively. The correlation coefficients between wood and cellulose from YAK are high for carbon as well for oxygen (Table 1b). The differences between whole wood and cellulose for the period 1900-2001 are $1.75 \%$ for $\delta^{13} \mathrm{C}$ and $3.56 \%$ for $\delta^{18} \mathrm{O}$. The mean isotope values for carbon are $-25.8 \%$ and $-24.05 \%$ and oxygen $15.5 \%$ and $19.06 \%$, for whole wood and cellulose, respectively.

\section{Climatological analysis}

Monthly and annual temperature and precipitation data. The range of mean temperature and precipitation for the closest weather stations 'Hatanga' (TAY) and 'Chokurdach' (YAK) are presented for the common period from 1929 to 2003 (Table 2). We split the analyzed period to equal parts with the goal to reveal changes or similarities in the data sets for the beginning and the end of 20th century.

The June air temperature changed in TAY less than in YAK when comparing the last 37 years to the earlier period, while the July air temperature was relatively constant for both regions. The temperature of August 
Table 1 Correlation coefficients between tree-ring width (TRW) index, maximum latewood density (MXD) and stable isotope $\left(\delta^{13} \mathrm{C}\right.$ and $\delta^{18} \mathrm{O}$ of whole wood and cellulose) chronologies for the period 1900-2001 for (a) eastern Taimyr and (b) for north-eastern Yakutia

\begin{tabular}{|c|c|c|c|c|c|c|}
\hline Parameter & TRW & MXD & $\delta^{13} \mathrm{C}$ of wood & $\delta^{13} \mathrm{C}$ of cellulose & $\delta^{18} \mathrm{O}$ of wood & $\delta^{18} \mathrm{O}$ of cellulose \\
\hline \multicolumn{7}{|l|}{ (a) } \\
\hline TRW & 1.00 & & & & & \\
\hline MXD & 0.62 & 1.00 & & & & \\
\hline$\delta^{13} \mathrm{C}$ of wood & 0.23 & 0.42 & 1.00 & & & \\
\hline$\delta^{13} \mathrm{C}$ of cellulose & & 0.37 & 0.84 & 1.00 & & \\
\hline$\delta^{18} \mathrm{O}$ of wood & 0.35 & 0.34 & 0.33 & 0.35 & 1.00 & \\
\hline$\delta^{18} \mathrm{O}$ of cellulose & & & 0.23 & 0.32 & 0.58 & 1.00 \\
\hline \multicolumn{7}{|l|}{ (b) } \\
\hline TRW & 1.00 & & & & & \\
\hline MXD & 0.59 & 1.00 & & & & \\
\hline$\delta^{13} \mathrm{C}$ of wood & & 0.49 & 1.00 & & & \\
\hline$\delta^{13} \mathrm{C}$ of cellulose & & 0.48 & 0.87 & 1.00 & & \\
\hline$\delta^{18} \mathrm{O}$ of wood & & & 0.33 & & 1.00 & \\
\hline$\delta^{18} \mathrm{O}$ of cellulose & & 0.32 & 0.56 & 0.47 & 0.45 & 1.00 \\
\hline
\end{tabular}

Level of significance is $P<0.05$. Only significant correlation coefficients are presented.

Table 2 Monthly and annual temperature and precipitation data of the investigated sites (only months shown, which are significantly correlated with tree-ring parameters and stable isotope chronologies)

\begin{tabular}{llllllll}
\hline Region & Period & T-June $\left({ }^{\circ} \mathrm{C}\right)$ & T-July $\left({ }^{\circ} \mathrm{C}\right)$ & T-August $\left({ }^{\circ} \mathrm{C}\right)$ & T-annual $\left({ }^{\circ} \mathrm{C}\right)$ & P-July $(\mathrm{mm})$ & P-annual $(\mathrm{mm})$ \\
\hline TAY & $1929-1966$ & 5.31 & 12.55 & 8.87 & -12.85 & 44.51 & 193.91 \\
& $1966-2003$ & 5.28 & 12.49 & 9.49 & -13.09 & 37.82 & 220.72 \\
& $1929-2003$ & 5.29 & 12.52 & 9.18 & -12.97 & 41.16 & 207.31 \\
YAK & $1929-1966$ & 7.32 & 10.76 & 7.86 & -13.71 & 28.79 & 159.21 \\
& $1966-2003$ & 6.74 & 10.73 & 7.57 & -14.24 & 34.59 & 177.05 \\
& $1929-2003$ & 7.03 & 10.74 & 7.71 & -13.97 & 31.69 & 168.13 \\
\hline
\end{tabular}

shows a higher increase for Taimyr than for north-eastern Yakutia. Also annual air temperatures are increased for the period 1966-2003 in comparison with 1929-1966, up to $0.53{ }^{\circ} \mathrm{C}$ for YAK and $0.24{ }^{\circ} \mathrm{C}$ for TAY. In contrast, the amount of annual precipitations shows increasing trends for the last 37 years for both sites, while July precipitation increases only for YAK (Table 2).

We calculated simple Pearson's correlation coefficients between all tree-ring parameters and monthly temperature and precipitation data from TAY (Fig. 3a) and YAK (Fig. 3b) for the period 1929-2001. Mainly, June and July air temperatures show positive significant correlations with radial tree growth, latewood density and stable isotopes for both sites (Fig. 3a, b). The cellulose and whole wood $\delta^{13} \mathrm{C}$ chronologies show negative significant correlations with July and August precipitation (Fig. 3a). The MXD chronology from TAY also shows negative significant correlations with precipitation of July and August (Fig. 3a), which was not observed in the YAK MXD chronology (Fig. 3b). Negative correlations were found when relating autumn temperatures of the previous years and spring temperatures of current years with tree-ring width and latewood density. A negative correlation was also found between temperature of February and carbon isotope values $(-0.30$ for cellulose and -0.29 for whole wood) (Fig. 3a). In contrast, we found positive significant correlation between the temperature of February and $\delta^{18} \mathrm{O}$ of cellulose for north-eastern Yakutia (Fig. 3b). Regarding annual temperatures, the correlations to $\delta^{13} \mathrm{C}$ of whole wood and cellulose from north-eastern Yakutia were weak but statistically significant $(r=0.21$; $P<0.05)$.

Negative correlations with annual precipitation were found for tree-ring width $(r=-0.30 ; P<0.05)$, maximum density $(r=-0.33 ; P<0.05)$ and $\delta^{13} \mathrm{C}(r=-0.35 ; P<0.05)$ and $\delta^{18} \mathrm{O}$ of whole wood $(r=-0.26 ; P<0.05)$, for the period 1929-2003, while this was not the case for $\delta^{13} \mathrm{C}$ and $\delta^{18} \mathrm{O}$ of cellulose.

Five-day average temperature data. For revealing differences and/or similarities in the responses of trees from two Siberian sites at the beginning of the growth 

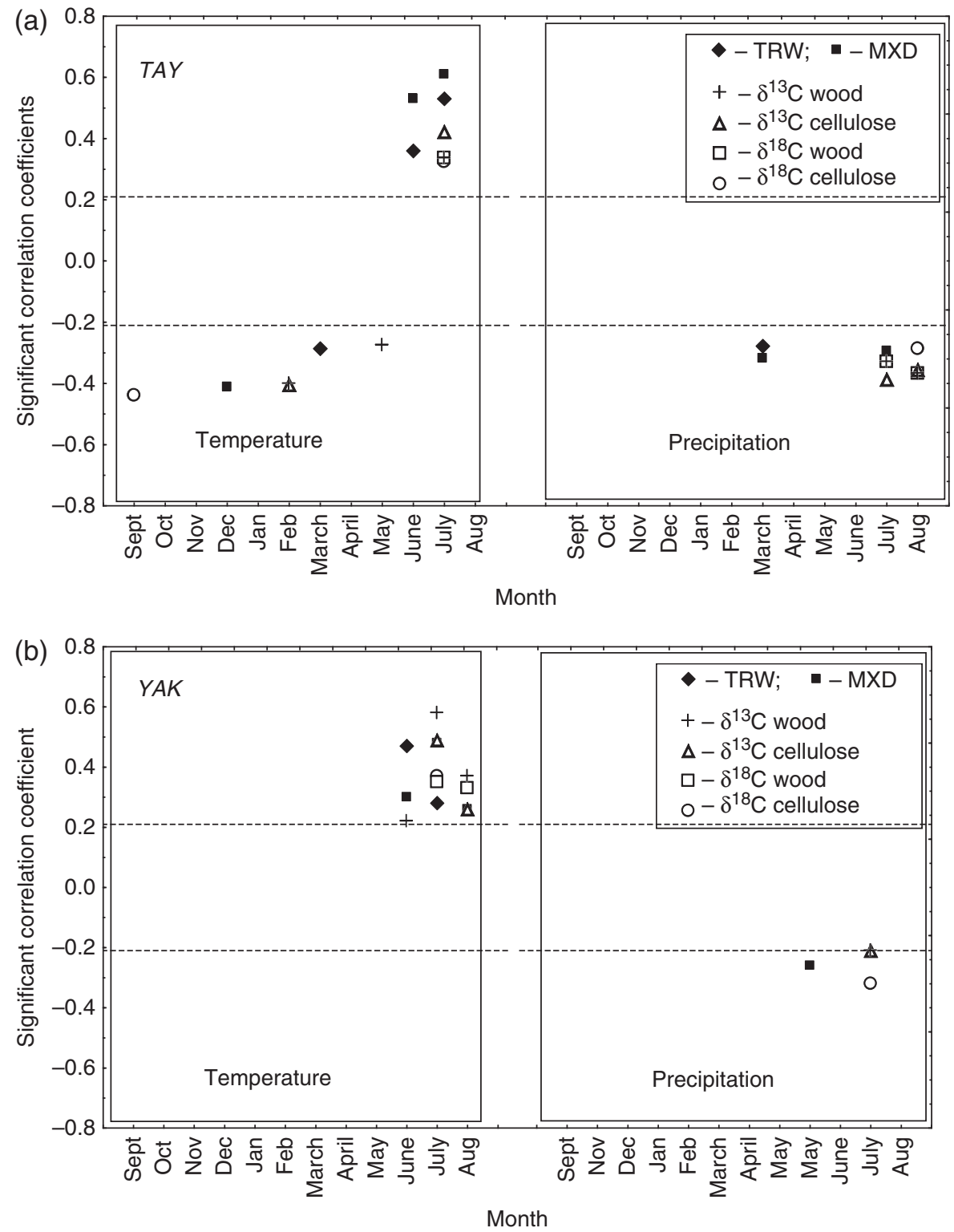

Fig. 3 Correlation coefficients between tree-ring width index (TRW), maximum latewood density (MXD), stable isotope chronologies $\left(\delta^{13} \mathrm{C}, \delta^{18} \mathrm{O}\right.$ of whole wood and cellulose) and monthly temperature and precipitation from eastern Taimyr (TAY) (a) and north-eastern Yakutia (YAK) (b). On this figures we present only significant values $(P<0.05)$. All symbols are identical for both analyzed regions. The dotted lines are the level of significance.

season we calculated correlation coefficients between all tree-ring parameters and pentad temperatures (Fig. 4a, b). We observed positive significant correlations with treering width, latewood density, $\delta^{13} \mathrm{C}, \delta^{18} \mathrm{O}$ of whole wood and cellulose for eastern Taimyr (Fig. 4a) and significant correlations for all these parameters for north-eastern Yakutia except for $\delta^{18} \mathrm{O}$ of whole wood and cellulose (Fig. 4b). We found that tree-ring width reflects the temperature signal at the end of June and beginning of July for eastern Taimyr and at the beginning of June for north-eastern Yakutia confirming this date as the earliest start of tree radial growth in the eastern part of Siberia. The maximum latewood density shows significant correlations from the middle of June till middle of August for both regions (Fig. 4b). These relationships show that the end of the growing season is approximately at the same time for both regions but the beginning is at different times. The $\delta^{13} \mathrm{C}$ of whole wood and cellulose significantly correlated from the middle of June till the middle of August for TAY (Fig. 4a), while for YAK from the end of June to the beginning of August (Fig. 4b). Whereas the $\delta^{18} \mathrm{O}$ of whole wood chronology from 

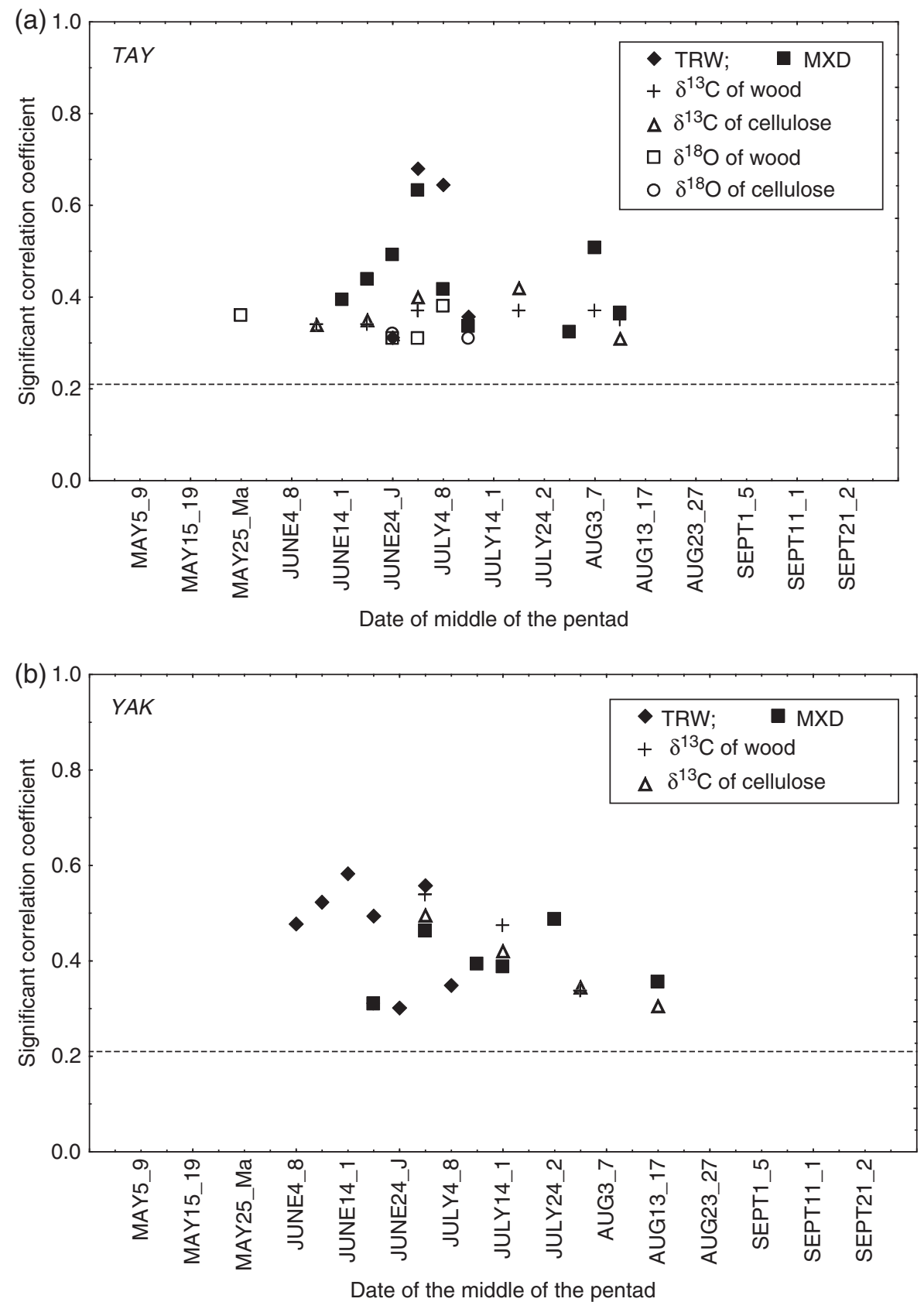

Fig. 4 Correlation coefficients between tree-ring width indices (TRW), maximum latewood density (MXD), stable isotope chronologies $\left(\delta^{13} \mathrm{C}, \delta^{18} \mathrm{O}\right.$ of whole wood and cellulose) and 5-day average temperature data (pentads data) from eastern Taimyr (TAY) (a) and northeastern Yakutia (YAK) (b). These figures contain only significant values $(P<0.05)$. All symbols are identical for both analyzed regions.

eastern Taimyr shows an earliest response with temperatures at the end of May till the beginning of July, $\delta^{18} \mathrm{O}$ of cellulose shows a late response from the end of June till middle of July (Fig. 4a). On the other hand, we did not find any significant correlation between $\delta^{18} \mathrm{O}$ chronologies from YAK and 5-day temperature data for the analyzed period, but monthly temperature data indicate a positive relationship between $\delta^{18} \mathrm{O}$ of whole wood, cellulose and July air temperature $(r=0.35$ and $0.37 ; \quad P<0.05$, respectively) and July precipitation $(r=-0.31$ and $-0.32 ; P<0.05$, respectively) for the period 1900-2004.

Comparison between eastern Taimyr and north-eastern Yakutia. We observed significant negative correlations between the chronologies from Taimyr (TAY) and 

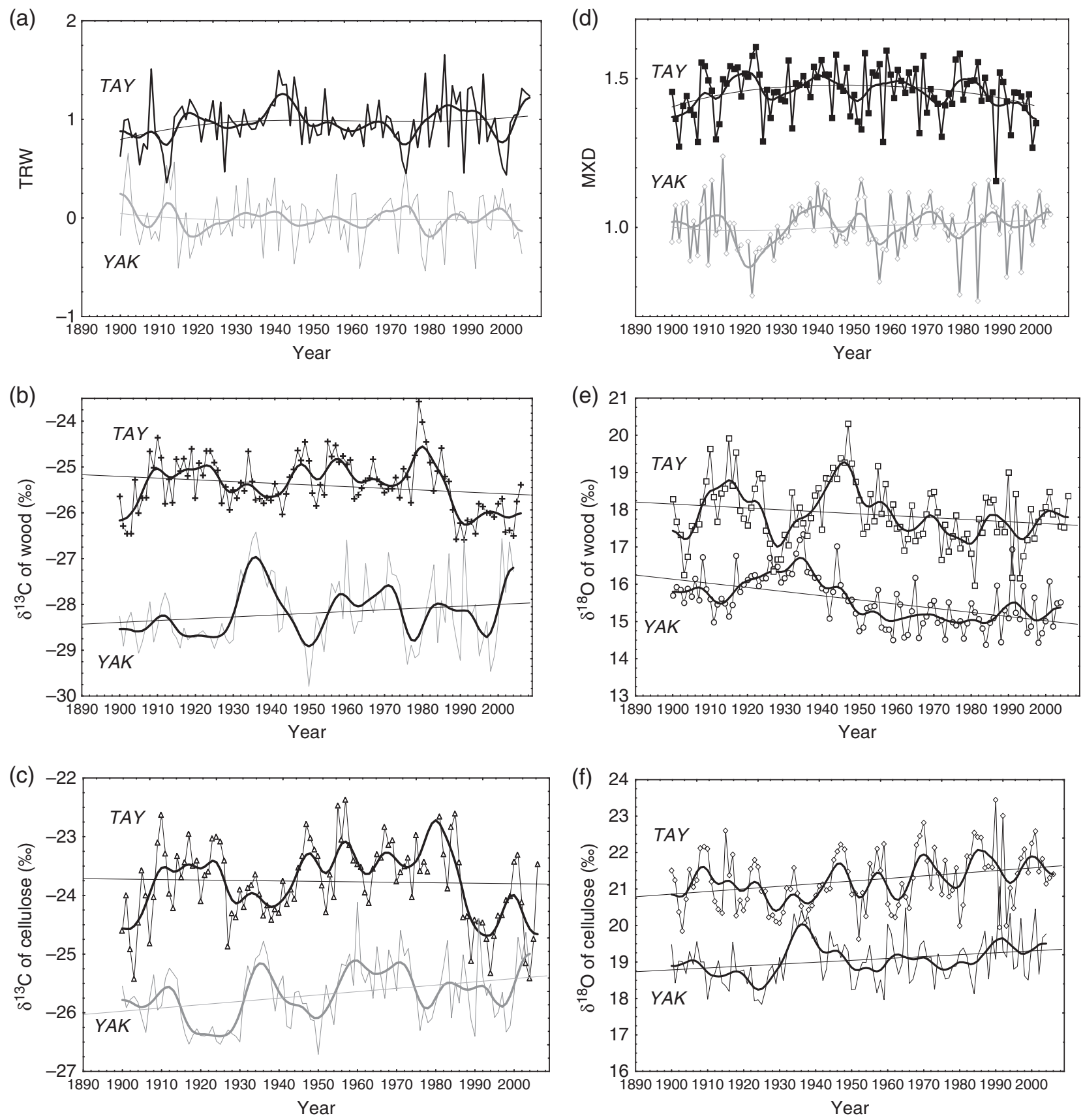

Fig. 5 The tree-ring index (a), maximum latewood density (d), $\delta^{13} \mathrm{C}$ and $\delta^{18} \mathrm{O}$ of whole wood (b, e) and cellulose (c, $\mathrm{f}$ ) chronologies from eastern Taimyr (TAY) and north-eastern Yakutia (YAK). The chronologies are smoothed by the Hamming 11-year window.

north-eastern Yakutia (YAK) regarding tree-ring width, latewood density and $\delta^{13} \mathrm{C}$ of whole wood. For TRW, negative correlations were found in year-to-year variability for the period 1900-2004 $(r=-0.30)$ and 1945-2004 $(r=-0.39)$ as well as in 11-year smoothed chronologies $(r=-0.40$ and -0.55$)$ for both periods respectively (Fig. 5a). These negative relationships were also found between smoothed latewood chronologies from TAY and YAK for 1900-2001 and
1945-2001 $(r=-0.23$ and $-0.37 ; P<0.05)$, respectively (Fig. 5d). The $\delta^{13} \mathrm{C}$ whole wood chronologies from both analyzed regions showed weak negative correlations between each other $(r=-0.21 ; P<0.05)$ (Fig. 5b), whereas we found no significant correlations between the $\delta^{13} \mathrm{C}$ cellulose chronologies (Fig. 5c).

In contrast, we found positive correlation coefficients between $\delta^{18} \mathrm{O}$ in cellulose from eastern Taimyr and north-eastern Yakutia for the period 1945-2004 for 
the smoothed chronologies $(r=0.32 ; P<0.05)$ (Fig. 5f). Both oxygen isotope chronologies in cellulose show increasing trends after 1930. We did not find any significant correlations between $\delta^{18} \mathrm{O}$ whole wood chronologies of the two regions, although the trends were similar (Fig. 5e).

Spatial patterns (north-eastern Yakutia, eastern Taimyr and northern Finland). Using tree-ring width index, latewood density, stable isotope chronologies from TAY and YAK we calculated correlation coefficients with GJT within the coordinates $20-150^{\circ} \mathrm{E}$ and $50-80^{\circ} \mathrm{N}$ for the period 1901-2002 (Fig. 6). The diagram of spatial dimension of TRW for YAK and TAY (Fig. 6a, g) shows the areas of significant correlation coefficients around analyzed regions. Higher correlation coefficients and larger areas of their distributions are found for MXD (Fig. 6b, h). From the diagram we can see differences in the temperature response between TAY and YAK. In our climatological analysis we revealed that June is the determining month for tree growth in YAK and July for TAY. The spatial patterns of correlations confirm these differences. $\delta^{13} \mathrm{C}$ of whole wood and cellulose from YAK (Fig. 6c, d) show high correlations with GJT in comparison with TRW (Fig. 6a) and show widespread dimension along the Eurasian north. The GJT and $\delta^{13} \mathrm{C}$ of whole wood and cellulose from TAY show negative correlation coefficients with YAK $(r=-0.5 ; P<10 \%)$ (Fig. 6i, j). The areas of significant relationships between carbon and GJT are smaller than for oxygen, which cover large distances from north to south (Fig. 6k, 1). The $\delta^{18} \mathrm{O}$ of wood and cellulose from YAK shows lower correlation coefficients and covers a smaller area in comparison with $\delta^{13} \mathrm{C}$ (Fig. 6e, f). The negative relationship between $\delta^{13} \mathrm{C}$ of whole wood and GJT is higher for cellulose and very widespread for YAK, partly reaching to FIN (Fig. 6c). Also the $\delta^{13} \mathrm{C}$ cellulose chronology obtained from Taimyr shows a higher correlation with GJT than wood (Fig. 6j). The oxygen isotope signals obtained from YAK trees show widespread negative patterns toward the West Siberian Lowland and the Kola Peninsula (Fig. 6e, f).

Stable isotope chronologies along the subarctic circle (northeastern Yakutia, eastern Taimyr, northern Finland and Greenland). As mentioned above, we did not find any significant correlations between $\delta^{13} \mathrm{C}$ of TAY and YAK cellulose chronologies. However, we found significant correlations between cellulose $\delta^{13} \mathrm{C}$ chronologies from Taimyr and northern Finland (Gagen et al., 2007) in yearto-year variability for the period 1945-2002 $(r=0.31)$ and in smoothed chronologies for 1900-2002 $(r=0.28)$ and for 1945-2002 ( $r=0.60 ; P<0.05)$, respectively (Fig. 7). The $\delta^{13} \mathrm{C}$ chronologies in cellulose from TAY and FIN show similar decreasing trends after 1940.

The comparison of the $\delta^{18} \mathrm{O}$ data from a Greenland ice core and $\delta^{18} \mathrm{O}$ in cellulose from Siberian trees (TAY, YAK) showed common climatic signals along the subarctic circle. We found a high coherence and a statistically significant relationship $(r=0.80 ; P<0.05)$ between GISP2 and YAK for the period 1900-1986 for smoothed chronologies (Fig. 8), whereas the $\delta^{18} \mathrm{O}$ cellulose chronology from Taimyr showed a very different pattern.

The NAO signature in the tree-ring parameters of northern Siberian larch trees. The tree-ring index chronologies from TAY and YAK show opposite patterns compared with NAO of February (Fig. 9a). Negative correlations to NAO were found for smoothed tree-ring width index chronology, latewood density and $\delta^{13} \mathrm{C}$ of whole wood from Taimyr and north-eastern Yakutia for the whole analyzed period 1900-2000 and for the last fifty years 1950-2000 (Table 3). During the positive phase of NAO after the 1980s we observed negative tree-ring index, late wood density (Fig. 9b) and carbon (Fig. 9c) patterns for both regions, while for oxygen we found positive correlations and overlapping (synchronous) patterns with NAO (Fig. 9d).

\section{Discussion}

\section{Seasonality}

Based on tree-ring width and stable isotope analysis we found that in the eastern part of Siberia (YAK) the tree growth season starts earlier than in north-central Siberia (TAY). Previous studies showed that seasonality in these regions is dominated by the variability of snow melt and strongly depends on the spring temperatures, which therefore play an important role in starting tree growth forming (Abaimov et al., 1997; Vaganov et al., 1999). Recently, numerous papers reported about shifting vegetation seasons to the earlier periods in northern regions due to a warming trend (Vaganov et al., 1999; Briffa et al., 2001). In contrast to the tree-ring width records, the signal obtained from the whole wood $\delta^{18} \mathrm{O}$ Taimyr chronology indicated an even earlier temperature response of trees already at the end of May. This relationship could indicate the beginning of snow melt and root physiological activity in this region as soon as temperatures are $>0{ }^{\circ} \mathrm{C}$ (Vaganov et al., 1996; Abaimov et al., 1997). However, the $\delta^{18} \mathrm{O}$ whole wood and cellulose chronologies from north-eastern Yakutia did not show any significant response indicated by 5 days average temperature data. Possible explanation of this could be the complex soil hydrology. Even in the beginning of the growth season when temperature of 
(a) TRW (YAK)

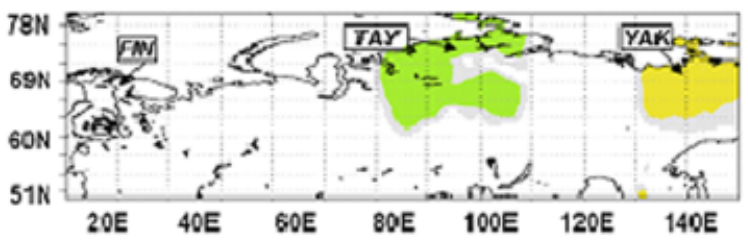

(b) $M X D(Y A K)$

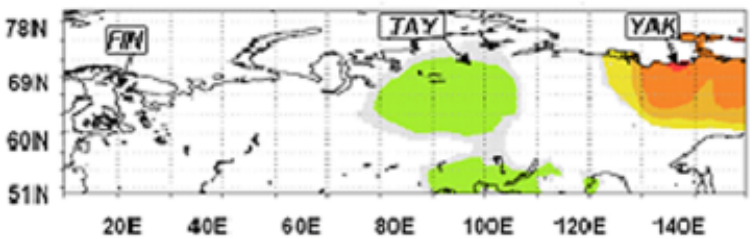

(c) $\delta^{13} \mathrm{C}$ of whole wood (YAK)

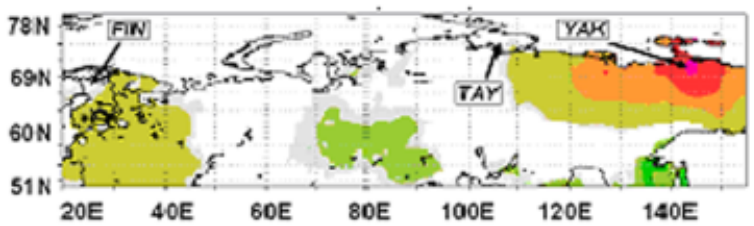

(d) $\delta^{13} \mathrm{C}$ of cellulose (YAK)

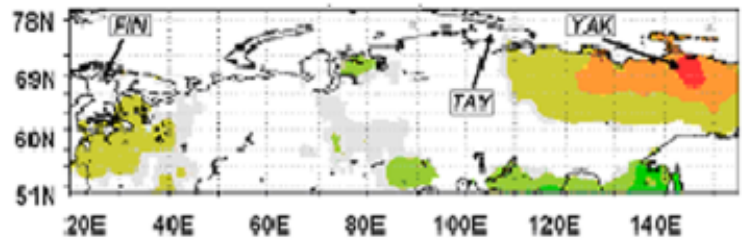

(e) $\delta^{18} \mathrm{O}$ of whole wood (YAK)

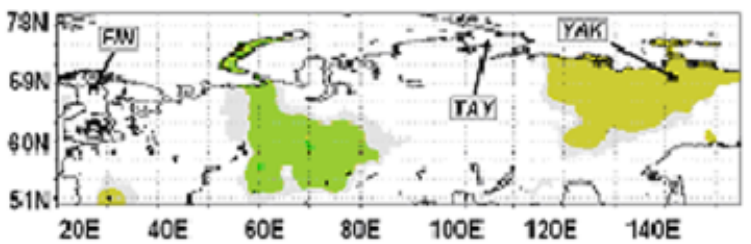

(f) $\delta^{18} \mathrm{O}$ of cellulose (YAK)

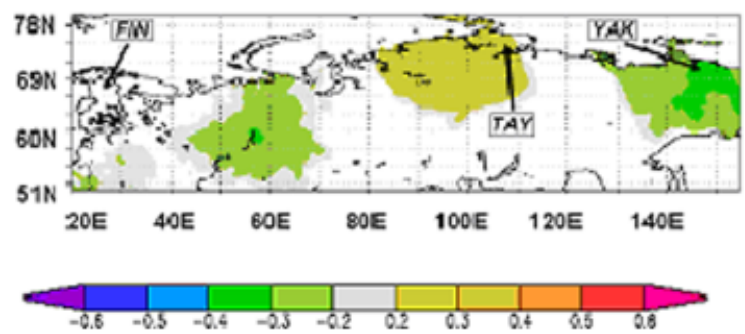

(g) TRW (TAY)

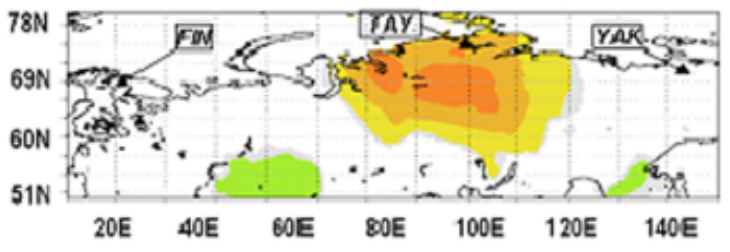

(h) $M X D(T A Y)$

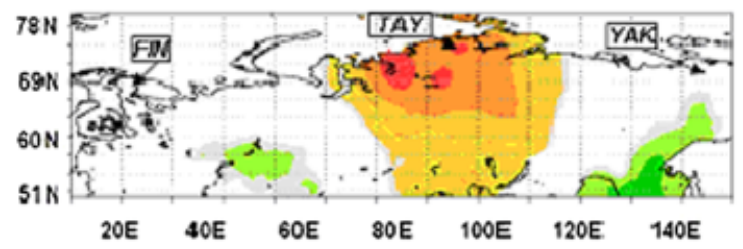

(i) $\delta^{13} \mathrm{C}$ of whole wood (TAY)

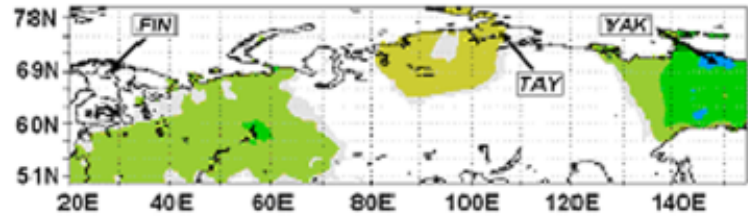

(j) $\delta^{13} \mathrm{C}$ of cellulose (TAY)

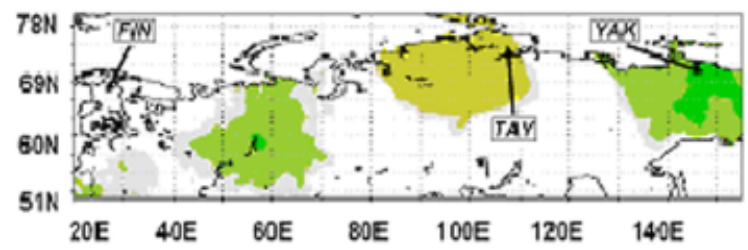

(k) $\delta^{18} \mathrm{O}$ of whole wood (TAY)

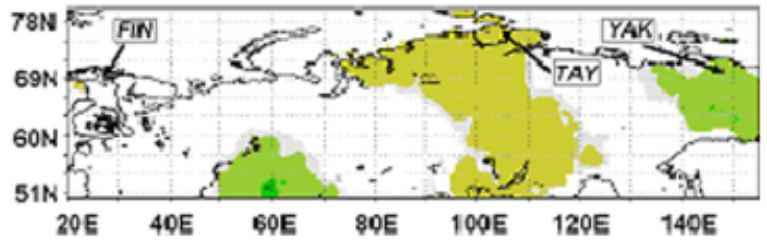

(I) $\delta^{18} \mathrm{O}$ of cellulose (TAY)

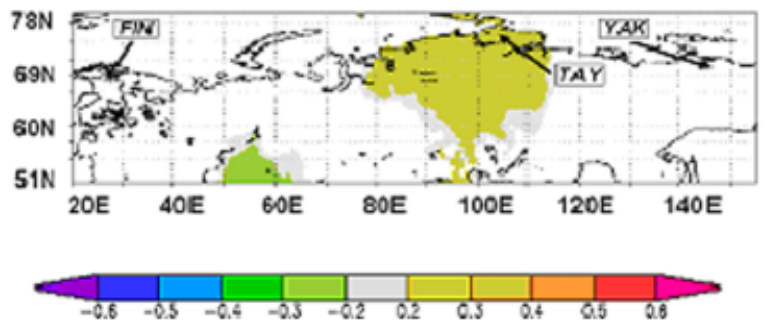

Fig. 6 Spatial dimension of correlation coefficients between tree-ring parameters, stable isotopes and July air temperature data obtained by grid data (http://climexp.knmi.nl) with a temporal resolution of up to $2.1 \times 0.5^{\circ}$ grad, $P<10 \%$ for the period $1901-2001$. The colors indicate the correlations, negative correlations are represented by blue to green colors, whereas positive correlations are represented by red to yellow colors (see the color scales at the bottom of the figure panels). 


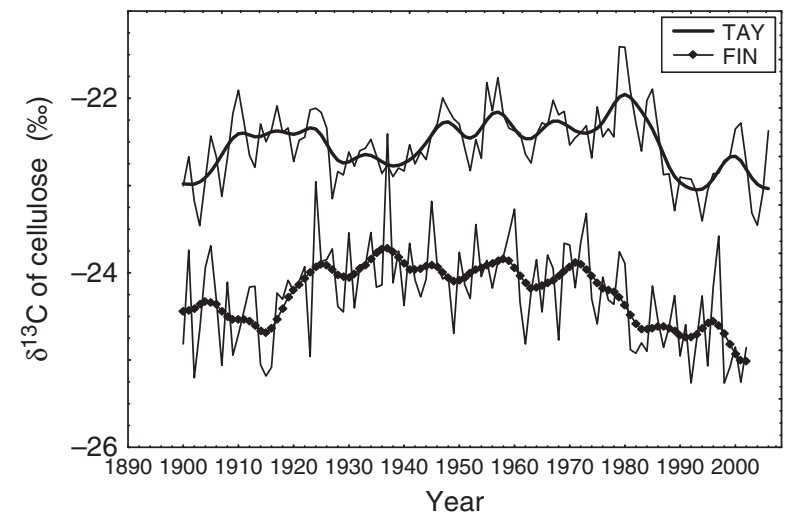

Fig. 7 The $\delta^{13} \mathrm{C}$ of cellulose chronologies from eastern Taimyr (TAY) and northern Finland (FIN) are shown. The data are smoothed by the Hamming 11-year window.

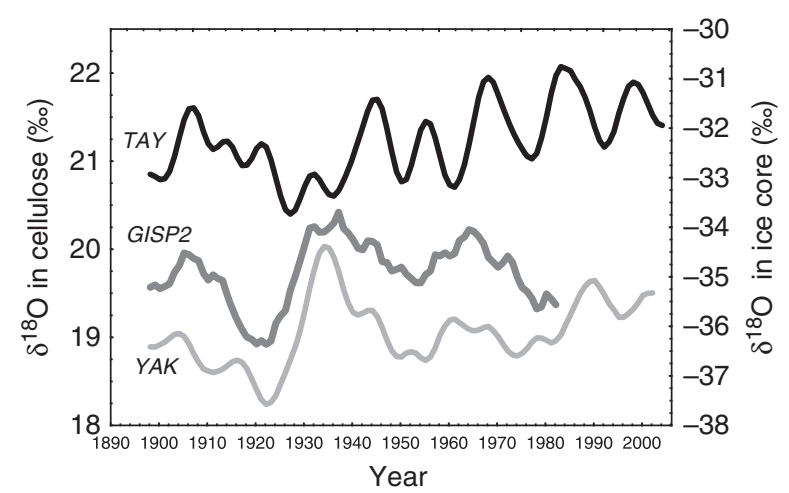

Fig. 8 The $\delta^{18} \mathrm{O}$ of cellulose chronologies from eastern Taimyr and north-eastern Yakutia in comparison with the $\delta^{18} \mathrm{O}$ in Greenland ice core chronology. The data are smoothed by the Hamming 11-year window.

June is the most important factor for tree growth the soil is still frozen and the snow cover in this region is minimal in comparison with eastern Taimyr. Our results show that the combination of ring width and stable isotopes allows to better analyze the onset of tree physiological activity and the changes in environmental conditions that are required for tree growth to start.

\section{Drought $/ \mathrm{CO}_{2}$ saturation}

According to weather station data for the last 37 years the amount of June and July precipitation was slightly decreasing for TAY and slightly increasing for YAK. Decreasing precipitation during the analyzed period for TAY and along with a slight annual temperature increase, could lead to deeper thawing of permafrost and to hardly freezing soil back (Boike et al., 1998; Euskirchen et al., 2006). In line with the lower amount of available water and higher temperature in TAY, the
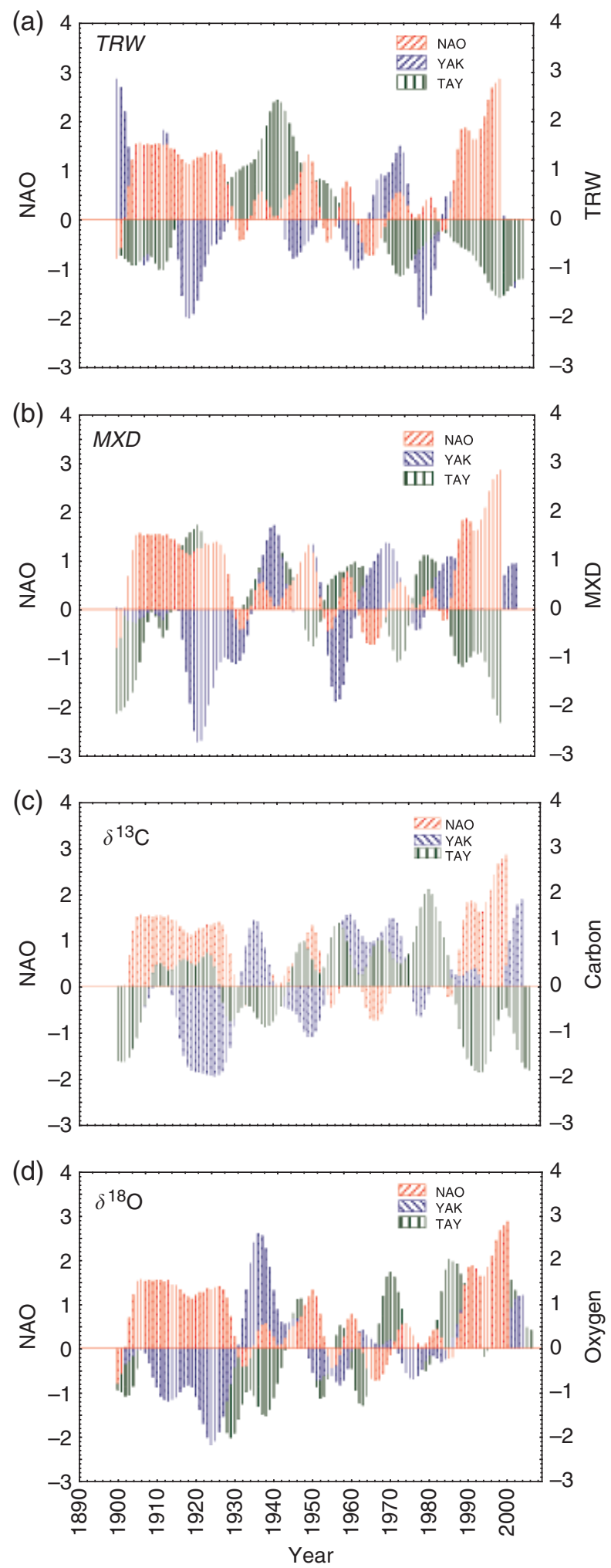

Fig. 9 The positive and negative phases of the normalized North Atlantic Oscillation index chronology in comparison with the normalized chronologies (a) tree-ring width index, (b) latewood density, (c) $\delta^{13} \mathrm{C}$ of cellulose and (d) $\delta^{18} \mathrm{O}$ of cellulose from eastern Taimyr and north-eastern Yakutia for the period 1900-2000. 
Table 3 The significant correlation coefficients between tree-ring width (TRW) index, latewood density (MXD), stable isotope chronologies from eastern Taimyr and north-eastern Yakutia and index of North Atlantic Oscillation for February

\begin{tabular}{|c|c|c|c|c|c|c|c|}
\hline \multirow[b]{2}{*}{ Region } & \multirow[b]{2}{*}{ Period } & \multicolumn{6}{|c|}{ Parameter } \\
\hline & & TRW & MXD & $\delta^{13} \mathrm{C}$ of wood & $\delta^{13} \mathrm{C}$ of cellulose & $\delta^{18} \mathrm{O}$ of wood & $\delta^{18} \mathrm{O}$ of cellulose \\
\hline TAY & 1900-2000 & -0.35 & -0.36 & -0.28 & -0.34 & & \\
\hline & 1950-2000 & -0.53 & -0.77 & -0.71 & -0.72 & & \\
\hline YAK & $\begin{array}{l}1900-2000 \\
1950-2000\end{array}$ & & & $\begin{array}{l}-0.41 \\
-0.46\end{array}$ & $\begin{array}{l}-0.42 \\
-0.42\end{array}$ & 0.28 & 0.55 \\
\hline
\end{tabular}

decreasing $\delta^{13} \mathrm{C}$ and increasing $\delta^{18} \mathrm{O}$ of cellulose after 1970 s could indicate a reduction in photosynthetic capacity and stomatal conductance and development of a drought situation based on isotope fractionation theory (Scheidegger et al., 2000). A similar conclusion was recently drawn for a somewhat less northern site $\left(64^{\circ} \mathrm{N}\right)$ also in central Siberia, where strong isotope trends over the 20th century were observed (Sidorova et al., 2009). In addition to the changes in climatic conditions, also the influence of increasing atmospheric $\mathrm{CO}_{2}$ has to be considered. The limited access to nutrients in the permafrost region suggests strongly a $\mathrm{CO}_{2}$ saturation of these trees. As the photosynthetic capacity can no longer be enhanced the intercellular $\mathrm{CO}_{2}$ concentration will increase along with the ambient $\mathrm{CO}_{2}$. Thus the $\Delta{ }^{13} \mathrm{CO}_{2}$ discrimination will increase with increasing $\mathrm{CO}_{2}$ concentration resulting in a continuous decrease of $\delta^{13} \mathrm{C}$. As $\delta^{13} \mathrm{C}$ decreases due to elevating ambient $\mathrm{CO}_{2}$ concentrations the reduction in stomatal conductance can detected by an increase in $\delta^{18} \mathrm{O}$. A previous stable isotope study for Siberian Scots pine in Turuchansk $\left(66^{\circ} \mathrm{N}\right)$ showed a declining trend in $\Delta^{13} \mathrm{C}_{\mathrm{c}}$ for the second half of the 20th century. Arneth et al. (2002) explained the trend by tree responses to increasing atmospheric $\mathrm{CO}_{2}$ concentration and increasing water use efficiency due to increasing soil water deficit and declining air humidity.

\section{Trends over recent decades/wood and cellulose}

Declining trends for the last decades, in $\delta^{13} \mathrm{C}$ of cellulose were not only found in eastern Taimyr, but also in Finland, even after $\delta^{13} \mathrm{C}$ correction for the atmospheric $\mathrm{CO}_{2}$, showing a possibly wide-spread phenomenon (McCarroll et al., 2009). Similarly, declining trends in tree growth have been reported for many areas which could be explained by (a) drought stress (Barber et al., 2000; Wilmking et al., 2005; Sidorova et al., 2008), (b) timedependent responses to recent warming (increasing temperature and $\mathrm{CO}_{2}$ ) (Briffa et al., 1998), (c) delayed snow melt (Vaganov et al., 1999) and (d) seasonality changes (Skomarkova et al., 2006).
The oxygen isotopes, on the other hand, do not show unambiguous trends. The $\delta^{18} \mathrm{O}$ cellulose chronology obtained from eastern Taimyr shows a slight increase after 1960s, while $\delta^{18} \mathrm{O}$ of whole wood show slight decreases. Previous studies, which were carried out for the Eurasian north showed declining trends for $\delta^{18} \mathrm{O}$ from wood chronologies and were explained by changes in the seasonality of precipitation (Saurer et al., 2002). Although our wood $\delta^{18} \mathrm{O}$ data agreed with earlier data the analysis for $\delta^{18} \mathrm{O}$ of cellulose, which was carried out for the northern region for the first time show an opposite pattern to the whole wood. The reason for these differences could be explained by changes in the composition of different wood constituents (e.g. cellulose/lignin ratio, sucrose, starch) (Sidorova et al., 2008), or in the composition differences of heart and sapwood (D'Alessandro et al., 2004) induced by climatic changes (temperature/precipitation) or elevated $\mathrm{CO}_{2}$. Differences between whole wood and cellulose up to $4 \%$ were found for oxygen for both analyzed Siberian regions $(17.9 \%$ for wood and $21.34 \%$ for cellulose - TAY; $15.5 \%$ for wood and $19.06 \%$ for cellulose - YAK), respectively, where isotopic exchange with hydroxyl groups in metabolic reactions in needles and stems has to be considered (Sternberg et al., 1986; Saurer et al., 1997; Roden \& Ehleringer, 2000). The increasing $\delta^{18} \mathrm{O}$ values from east to west can be explained by the latitude effect (Saurer et al., 2002). The differences between whole wood and cellulose for carbon were up to $2 \%$ for TAY $(-25.4$ for wood and -23.76 for cellulose) and for YAK $(-25.8$ for wood and -24.05 for cellulose), respectively. For a better understanding of mechanisms causing these differences between $\delta^{18} \mathrm{O}$ of whole wood and cellulose and different trends over time, the compound specific isotope analysis would be needed.

\section{Spatial patterns in Siberia}

We analyzed the spatial dimension of correlations between our site tree-ring and stable isotope data and temperature to get insight into the patterns of climate change (Fig. 6). The climate in the vast territory of 
northern Eurasia, where there are little topographic barriers, clearly is controlled by large-scale atmospheric pressure gradients. Therefore correlations between climate over large distances can be expected. Indeed, we observed that correlations from the YAK site to July temperatures at locations thousands of kilometers away can be found, with the area of correlation extending mostly in the direction of east to west. Respective correlation for the central Siberian site TAY were also extending far, but more from the north to the south. However, we also observed an interesting opposite patterns of climatic changes between the two Siberian regions, in that areas that correlate positively with TAY correlate negatively with YAK, mainly for ring width, density and $\delta^{13} \mathrm{C}$ (see Fig. 6a, b, f, i, j, k). This same opposite behavior was observed for the temporal changes in ring width, density and $\delta^{13} \mathrm{C}$ (Fig. 5), indicating that relatively warm temperatures in one region are often occurring when temperatures in the other region are relatively cold. Opposite patterns of climate change as observed in our work challenge the wide-spread approach of averaging different chronologies for obtaining an Eurasian or even hemispheric temperature reconstruction, because the averaging will cancel out important regional differences in trends. This probably reflects changes in the atmospheric circulation that affect central and eastern Siberia differently. An earlier study showed an indirect link between tree-ring parameters from Eurasian north and the atmospheric circulation via the land temperature (Briffa et al., 2002). The authors assumed that the relationship between proxy series and its local climate is stationary meaning that the response of surface climate to atmospheric circulation variations will not change. Further it was shown that the network of tree-ring density chronologies exhibits spatially coherent modes of variability and that they are closely matched with summer temperature variations, in terms of similar spatial patterns and temporal evolution during the instrumental period. The improved results allow the reconstruction of the large-scale atmospheric circulation patterns that included precipitation-sensitive networks of tree-ring parameters around the Northern Hemisphere.

\section{$N A O$}

Changes in the Eurasian subarctic like temperature increase, thawing of permafrost, changes in seasonality (shifting of the beginning of the growth period) and changes in the amount of precipitations are linked to a positive phase of NAO (Hurrell, 1995; Boike et al., 1998; Vaganov et al., 1999; Serreze et al., 2000; Briffa et al., 2002; Stone et al., 2002; Sugimoto et al., 2002; Welker et al., 2005; Euskirchen et al., 2006). The NAO is a large-scale mode of atmospheric circulation, which has positive and negative phases. The positive and negative phases of the NAO are defined by the differences in pressure between the persistent low over Greenland and Iceland and the persistent high off the coast of Portugal. That is, the low has a lower atmospheric pressure and the high has a higher atmospheric pressure. During a positive $\mathrm{NAO}$, both systems are stronger than usual. During the negative phase of the NAO, both systems are weaker, lowering the difference in pressure between them. During a strong positive NAO index, the winds along this conduit pick up, and they push the storms toward Eurasian north with temperature increase and reduction/stability in precipitations, which are observed during the last 30 years (Hurrell, 1995; Serreze et al., 2000; Welker et al., 2005). The negative phases are characterized by high atmospheric pressure and temperature decrease. The positive relationship, which was found between February temperature and $\delta^{18} \mathrm{O}$ of cellulose for north-eastern Yakutia and the negative correlations between the temperature of February and $\delta^{13} \mathrm{C}$ of wood and cellulose for eastern Taimyr, could also be explained by the influence of NAO.

\section{Large scale}

The correlation analysis, which was carried out along the circumpolar circle revealed high correlation coefficients between the $\delta^{18} \mathrm{O}$ cellulose chronology from north-eastern Yakutia and Greenland ice core $\delta^{18} \mathrm{O}$ data, two locations separated by thousands of kilometers. It is interesting to note that Greenland and YAK are almost on opposite points of the polar sea (see Fig. 1). Climatic connections over such large distances are a result of atmospheric circulation patterns controlling the precipitations (Welker et al., 2005). The resulting temperature changes influence the freezing and thawing processes in the upper soil during several years. The different accessible sources of water (snow, rain and melting water) lead to an annual climatic signal similar to that accumulated in $\delta^{18} \mathrm{O}$ of ice cores. The positive correlations between oxygen isotope data at north-eastern Yakutia with Greenland ice cores indicate similarities in the nature of lowfrequency temperature variability during the recent period in these two regions. The revised pattern was observed for eastern Taimyr and accordingly no significant correlation was found for the recent period between these regions, in fact the temperature and precipitation patterns between eastern Taimyr and Greenland was opposite.

\section{Conclusions}

A new tree-ring index, $\delta^{13} \mathrm{C}$ and $\delta^{18} \mathrm{O}$ whole wood and cellulose chronology was obtained from TAY, which 
showed declining trends mainly in density and carbon isotopes during the period $1950-2006$. The $\delta^{13} \mathrm{C}$ of wood and cellulose chronologies from YAK did not show such declining trends as we found for $\delta^{13} \mathrm{C}$ of cellulose chronologies from TAY and FIN. This could indicate that forest ecosystems in north-eastern Siberia (YAK) still are less impacted by global warming than in northern parts of central Siberia (TAY).

The climatological analysis revealed that the stable isotope data $(\mathrm{C}, \mathrm{O})$ show a significant relationship with July precipitation, which is not observed in tree-ring widths. Complementary, latewood density chronology obtained from TAY show similar relationships as stable isotopes.

The isotope chronologies from the northern Siberian sites carry information on large-scale climate patterns. In particular, the $\delta^{18} \mathrm{O}$ signal from the eastern site YAK proved to have many wide-ranging connections, reaching as far as to Greenland and even responding to the NAO. This indicates that this location is ideal for capturing a representative climate signal for a large area, which is important in the context of climate reconstructions over millennia which are possible for this site (Sidorova et al., 2008). On the other hand, we found that the climatic signals inferred from tree-ring width and $\delta^{13} \mathrm{C}$ of whole wood and cellulose from TAY and YAK show inverse (negative correlations) response. This demands a cautionary note that climate variations are not uniform over northern Eurasia, but that different modes of atmospheric circulation can result in complex warming and cooling patterns.

The signal obtained from $\delta^{18} \mathrm{O}$ of whole wood and cellulose from TAY and YAK show similar trends for the common period $1900-2004$. The $\delta^{18} \mathrm{O}$ data could be considered as a climatic indicator for long-term climatic changes, which is confirmed by other proxies such as $\delta^{18} \mathrm{O}$ in Greenland ice core data and NAOs.

The temperature signal reflected in TRW, MXD and stable isotope chronologies from both Siberian regions show widespread dimension patterns from east to west (latitude effect) and from north to south (longitude effect).

For obtaining the quantitative information about climatic changes in the past the use of multidisciplinary approach by analyzing multiproxy data as performed in this study is needed.

\section{Acknowledgements}

This work was supported by Swiss National Science Foundation SNF_200021_121838/1, (PIOI2-119259/1), SCOPES program (No. IB73A0-111134), European Science Foundation BASIN-SIBAE (No. 596) and the grants of RFBR No. 09-05-98015-r_Sibir_a, RFBR No. 09-04-00803a, 07-04-00293-a. The authors thank Mary Gagen and Danny McCarroll from Swansea University, England for providing $\delta^{13} \mathrm{C}$ data from Laanila (Finland) and for their useful advises. This work was conducted in collaboration with the EU-funded Millennium project (017008).

\section{References}

Abaimov AP, Bondarev AI, Zyryanova OA, Shitova SA (1997) Polar Forests of Krasnoyarsk Region. Nauka Press, Novosibirsk.

ACIA (2005) Arctic Climate Impact Assessment. Cambridge University Press, Cambridge, NY, USA.

Arneth A, Lloyd J, Santruckova H et al. (2002) Response of central Siberian Scots pine to soil water deficit and long-term trends in atmospheric $\mathrm{CO}_{2}$ concentration. Global Biogeochemical Cycles, 16, 5/1-5/13, doi: 10.1029/2000GB001374.

Barber VA, Juday GP, Finney B (2000) Reduced growth of Alaskan white spruce in the twentieth century from temperature-induced drought stress. Nature, 405, 668-673.

Blackman RB, Tukey JW (1958) The Measurement of Power Spectra from the Point of View of Communication Engineering. Dover Publications, New York.

Boike J, Roth K, Overduin PP (1998) Thermal and hydrological dynamics of the active layer at a continuous permafrost site (Taymyr Peninsula, Siberia). Water Sources Research, 34, 355-363.

Briffa K, Osborn T, Schweingruber F et al. (2001) Low-frequency temperature variations from a northern tree ring density network. Geophysical Research, 106, 2929-2941.

Briffa K, Schweingruber F, Jones P, Osborn T (1998) Reduced sensitivity of recent tree growth to temperature at high northern latitudes. Nature, 391, 678-682.

Briffa KR, Osborn TJ, Schweingruber FH, Jones PD, Shiyatov SG, Vaganov EA (2002) Tree-ring width and density data around the Northern Hemisphere: part 2, spatial-temporal variability and associated climate patterns. The Holocene, 12, 759-789.

Cook ER, Kairiukstis LA (eds) (1990) Methods of Dendrochronology. Applications in the Environmental Sciences. Kluwer Academic Publishers, Dordrecht.

Craig H (1961) Isotopic variations in meteoric waters. Science, 133, 1702-1703.

D'Alessandro CM, Guerrieri MR, Saracino A (2004) Comparing carbon isotope composition of bulk wood and holocellulose from Quercus cerris, Fraxinus ornus and Pinus radiata tree rings. Forest, 1, 51-57.

D'Arrigo R, Wilson R, Liepert B, Cherubini P (2008) On the “Divergence Problem" in Northern forests: a review of the tree-ring evidence and possible causes. Global and Planetary Change, 60, 289-305.

Euskirchen ES, McGuire AD, Kicklighter DW, Zhuang Q, Clein JS (2006) Importance of recent shifts in soil thermal dynamics on growing season length, productivity, and carbon sequestration in terrestrial high-latitude ecosystems. Global Change Biology, 12, 731-750.

Farquhar GD, Ehleringer JR, Hubick KT (1989) Carbon isotope discrimination and photosynthesis. Annual Review of Plant Physiology and Plant Molecular Biology, 40, 503-537.

Farquhar GD, Lloyd J (1993) Carbon and oxygen isotope effects in the exchange of carbon dioxide between plants and the atmosphere. In: Stable Isotope and Plant Carbon/Water Relations (eds Ehleringer JR, Hall AE, Farquhar GD), pp. 47-70. Academic Press, San Diego. 
Francey RJ, Allison CE, Etheridge DM (1999) A 1000-year high precision record of $\delta^{13} \mathrm{C}$ in atmospheric $\mathrm{CO}_{2}$. Tellus, B51, 170-193.

Gagen MH, McCarroll D, Edouard J-L (2006) Combining ring width, density and stable carbon isotope proxies to enhance the climate signal in tree-rings: an example from the southern French Alps. Climatic Change, 78, 363-379.

Gagen MH, McCarrol D, Loader NJ, Robertson I, Jalkanen R, Anchukaitis KJ (2007) Exorcising the 'segment length curse' summer temperature reconstruction since AD 1640 using non de-trend stable carbon isotope ratios from line trees in northern Finland. The Holocene, 17, 433-444.

Gagen MH, McCarrol D, Robertson I, Loader NJ, Jalkanen R (2008) Do tree ring $\delta^{13} \mathrm{C}$ series from Pinus sylvestris in northern Fennoscandia contain long-term non-climatic trends? Chemical Geology, 252, 42-51.

Hughes MK, Vaganov EA, Shiyatov SG, Touchan R, Funkhouser G (1999) Twentieth-century summer warmth in northern Yakutia in a 600-year context. The Holocene, 9, 603-608.

Hurrell JW (1995) Decadal trends in the North Atlantic Oscillation and relationships to regional temperature and precipitation. Science, 269, 676-679.

IPCC (2007) 4th Assessment Report Intergovernmental Panel on Climate Change, Chap. 6, pp. 434-497. IPCC, Geneva, Switzerland.

Kirdyanov AV, Treydte KS, Nikolaev A, Helle G, Schleser GH (2008) Climatic signals in tree ring width, density and $\delta^{13} \mathrm{C}$ from larches in Eastern Siberia (Russia). Chemical Geology, 252, $31-41$.

Kirdyanov AV, Vaganov EA, Hughes MK (2007) Separating the climatic signal from tree-ring width and maximum latewood density records. Trees, 21, 37-44.

Loader NJ, Robertson I, Barker AC, Switsur VR, Waterhouse JS (1997) Improved technique for the batch processing of small whole wood samples to alpha-cellulose. Chemical Geology, 136, 313-317.

McCarroll D, Gagen MH, Loader NJ et al. (2009) Correction of tree ring stable carbon isotope chronologies for changes in the carbon dioxide content of the atmosphere. Geochimica et Cosmochimica Acta, 73, 1539-1547.

McCarroll D, Loader NJ (2004) Stable isotopes in tree rings. Quaternary Science Reviews, 23, 771-801.

McCarroll D, Pawellek F (2001) Stable carbon isotope ratios of Pinus sylvestris from northern Finland and the potential for extracting a climate signal from long Fennoscandian chronologies. The Holocene, 11, 517-526.

Meese DA, Alley RB, Gow AJ et al. (1994) The accumulation record from the GISP2 core as an indicator of climate change throughout the Holocene. Science, 266, 1680-1682.

Naurzbaev MM, Vaganov EA, Sidorova OV, Schweingruber FH (2002) Summer temperatures in eastern Taimyr inferred from a 2427-year late-Holocene tree-ring chronology and earlier floating series. The Holocene, 12, 727-736.

Roden JS, Ehleringer JR (2000) Hydrogen and oxygen isotope ratios of leaf water and tree ring cellulose for field grown riparian trees. Oecologia, 123, 481-489.

Saurer M, Aellen K, Siegwolf R (1997) Correlating $\delta^{13} \mathrm{C}$ and $\delta^{18} \mathrm{O}$ in cellulose of trees. Plant, Cell and Environment, 20, 1543-1550.

Saurer M, Schweingruber F, Vaganov EA, Schiyatov SG, Siegwolf R (2002) Spatial and temporal oxygen isotope trends at the northern tree-line in Eurasia. Geophysical Research Letters, 29, doi: 10.1029/2001GL013739.

Scheidegger Y, Saurer M, Bahn M, Siegwolf R (2000) Linking stable isotopes with stomatal conductance and photosynthetic capacity: a conceptual model. Oecologia, 125, 350-357.

Schweingruber FH (1996) Tree Rings and Environment Dendroecology. Paul Haupt Publisher, Bern.

Serreze MC, Walsh JE, Chapin FS (2000) Observational evidence of recent change in the northern high latitude environment. Climate Change, 46, 159-207.

Sidorova OV (2004) Analysis of the tree-ring and density characteristics of larch in the Eastern Taimyr. Proceedings of International Symposium, Saint-Petersburg. pp. 119-123.

Sidorova OV, Naurzbaev MM (2002) Response of Larix cajanderi to climatic changes at the upper timberline and in the Indigirka River valley. Lesovedenie, 2, 73-75 (in Russian).

Sidorova OV, Siegwolf RTW, Saurer M, Naurzbaev MM, Vaganov EA (2008) Isotopic composition $\left(\delta^{13} \mathrm{C}, \delta^{18} \mathrm{O}\right)$ in wood and cellulose of Siberian larch trees for early Medieval and recent periods. Geophysical Research Biogeosciences, 113, G02019, doi: 10.1029/2007JG000473.

Sidorova OV, Siegwolf RTW, Saurer M et al. (2009) Do centennial tree-ring and stable isotope trends of Larix gmelinii (Rupr.) indicate increasing water shortage in the Siberian North? Oecologia, in press, doi: 10.1007/s00442-009-1411-0.

Skomarkova MV, Vaganov EA, Mund M et al. (2006) Inter-annual and seasonal variability of radial growth, wood density and carbon isotope ratios ${ }^{13} \mathrm{C} /{ }^{12} \mathrm{C}$ in tree rings of beech (Fagus sylvatica) growing in Germany and Italy. Trees, 20, 571-586.

Sternberg L, Deniro MJ, Savidge R (1986) Oxygen isotope exchange between metabolites and water during biochemical reactions leading to cellulose synthesis. Plant Physiology, 82, 423-427.

Stone RS, Dutton EG, Harris JM (2002) Earlier spring snowmelt in northern Alaska as an indicator of climate change. Journal of Geophysical Research, 107, 4089, doi: 10.1029/2000JD000286.

Sugimoto A, Yanagisawa N, Naito D, Fujita N, Maximov TC (2002) Importance of permafrost as a source of water for plants in east Siberian taiga. Ecological Research, 17, 493-503.

Vaganov EA, Hughes MK, Kirdyanov AV, Schweingruber F, Silkin PP (1999) Influence of snowfall and melt timing on tree growth in subarctic Eurasia. Nature, 400, 149-151.

Vaganov EA, Naurazbaev MM, Schweingruber FH, Briffa KR, Moell M (1996) An 840-year tree-ring width chronology for Taimyr as an indicator of summer temperature changes. Dendrochronologia, 14, 193-205.

Vaganov EA, Shiyatov SG (1999) The role of dendroclimatical and dendrohydrological study in development of global and regional ecological problems. Siberian Ecological Journal, 6, 111-115.

Welker JM, Rayback S, Henry HR (2005) Arctic and North Atlantic Oscillation phase changes are recorded in the isotopes $\left(\delta^{18} \mathrm{O}\right.$ and $\left.\delta^{13} \mathrm{C}\right)$ of Cassiope tetragona plants. Global Change Biology, 11, 997-1002.

Wilmking M, D’Arrigo R, Jacoby G, Juday G (2005) Divergent growth responses in circumpolar boreal forests. Geophysical Research Letters, 32, L15715, doi: 10.1029/2005GLO23331.

Yakir DL, Sternberg L (2000) The use of stable isotopes to study ecosystem gas exchange. Oecologia, 123, 297-311. 